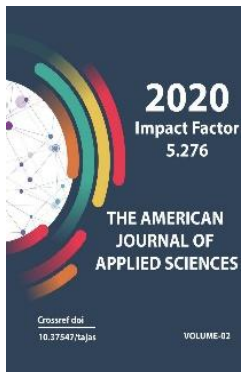

Journal Website: http://usajournalshub.c om/index,php/tajas

Copyright: Original content from this work may be used under the terms of the creative commons attributes 4.0 licence.

\section{Geoinformation Modeling Of Hydrogeological Processes Of The Akhangaran Underground Water Field}

\author{
Sh.S.Akhralov \\ Tashkent University Of Information Technologies Named After Muhammad Al-Khwarizmi, \\ Scientific-Innovation Center Of Information-Communication Technologies, Tashkent, \\ Uzbekistan.

\section{R.A.Yusupov} \\ Tashkent University Of Information Technologies Named After Muhammad Al-Khwarizmi, \\ Scientific-Innovation Center Of Information-Communication Technologies, Tashkent, \\ Uzbekistan.

\section{N.M.Mirzanova} \\ Tashkent University Of Information Technologies Named After Muhammad Al-Khwarizmi, \\ Scientific-Innovation Center Of Information-Communication Technologies, Tashkent, \\ Uzbekistan.

\section{F.U.Axrorov} \\ Tashkent University Of Information Technologies Named After Muhammad Al-Khwarizmi, \\ Scientific-Innovation Center Of Information-Communication Technologies, Tashkent, \\ Uzbekistan.
}

\title{
ABSTRACT
}

In the article the application issues of geographic information technologies and methods of mathematical modeling of geofiltration and geomigration processes of hydrogeological systems were discussed, as well as for information support of the groundwater monitoring system. The object of research are the Akhangaran aquifer, which is a large industrial area with intensification of agriculture, as well as densely populated, where industrial reproduction of water resources is established by designing water intake facilities using groundwater, also having huge data on regime, geological and hydrogeological aspects. The main goal of these researches is to learn the methodology for assessing groundwater resources by modeling to the GIS basis, theoretical and applied methods of mathematical analyses. The features are considered and the boundary and initial conditions are justified. The results are a research technique has been developed to simulate geofiltration and geomigration processes, to determine the balance of groundwater, and the hydrogeological parameters of the aquifer have been calculated from it. The calculated values of the natural resources of groundwater by the parameters of their level mode in the Ahangaran pool allowed establish the permissible convergence of resource estimates according to the amplitudes of fluctuations in the level of groundwater and according to geoinformation modeling. 


\section{KEYWORDS}

Mathematical modeling, geofiltration processes, geoinformation technology, topographic surfaces, groundwater, geofiltration schematization, finite-difference schemes, monitoring of the underground hydrosphere.

\section{INTRODUCTION}

Groundwater is the property of the state and is enshrined in laws "On Nature Management", "On Subsoil", etc. In the arid climate of the Republic of Uzbekistan, the main suppliers of fresh water suitable for drinking are river valleys. Significant groundwater reserves are concentrated in them, which are formed mainly due to filtration losses from surface watercourses and irrigation water infiltration [Mavlonov A.A.et al, 2011, p.35],[Mirzaev S.Sh.et al, 1974],[Hasanov A.S.et al, 2005, p.212].

An important direction of increasing the efficiency of the geological, agricultural and industrial sectors of the economy is the use of modern geographic information technologies for the information integration of processes. According to various estimates, up to $80 \%$ of the production cycle time is spent on the preparation and support of design models in high-tech production. This is related primarily to the high labor input and complexity of preparing the initial (visual-figurative) information. At present, mathematical and geoinformation models are being created in various areas of geological and hydrogeological science, and thematic electronic maps are also widely used. This product is becoming one of the common forms of presenting various kinds of information [Djumanov J.X., 2016, p.258],[Saidmuradov Zh.Z.et al, 2008, p.116].
ESRI geographic information systems (GIS)(ArcGIS, Arclnfo, ArcView, etc.) in such tasks are a powerful tool for data integration and analysis [Djumanov J.X., 2016, p.258]. With GIS technology, a development process is now occurring that is characteristic of the entire history of science and technology. Needs push to the creation of some visualized database, technical and information system for solving the problems of geology, reclamation hydrogeology and engineering geology.

There are various methods of geoinformation modeling, surface construction, topographic analysis and handling of inaccurate quantities, i.e. fuzzifications.Fuzzification is the establishment of a correspondence between the specific, usually numerical, value of a single input variable of a fuzzy inference system and the value of the membership function of the corresponding term of the input linguistic variable. When specifying for elements of a set the corresponding degree of belonging to this set, the theory of fuzzy sets is used, which was first proposed by the American mathematician L.Zadeh [Usmanov R.K. et al, 2007, p.37]. At present, the theory is actively developing, new scientific concepts and its applied areas are being formed. There is a tendency toward integration into a general theory of uncertainty analysis, where operations with fuzzy sets are one of the main ones. That is, information is turning into a general scientific concept, including the exchange of information between people, a 
person and a machine, the exchange of signals in the geological and plant world; transmission of signs from nature, from the geosphere to the computer; becomes one of the basic concepts of information and communication technologies.

Conducting research, evaluation and monitoring researches by traditional methods is associated with high labor and material costs, subjective dependence on the executor and the timeliness (inertia) of information; therefore, solving modern, complex engineering problems based on new computer technologies for three-dimensional modeling is an urgent problem.

\section{MATERIALS AND METHODS}

At leading research centers in the Netherlands, Denmark, Germany, Canada, Russia, and others, a number of software packages have been developed that focus on modeling hydrogeological systems, such as Visual MODFLOW (USA), Groundwater Modeling System (GMS), combining MODFLOW models, Brigham Yong University laboratories, Ground Water Vistas GWV DHI (Denmark), ModTech developed by Geolink Consulting (Russia), "the GWFS Geofiltration Modeling" software system. A number of researches were carried out on the application of finite-difference and numerical methods for modeling the geofiltration processes of groundwater, including [Djumanov J.X., 2016, p.28]:F.B.Abutaliev, J.Fried, I.K.Gavich, A.A.Samarsky, V.M.Shestakov, L.Luckner, U.U.Umarov, J.C.Refsgaard, L.M.MilneThomson, W.Kinzelbach, N.N.Verigin, I.Khabibullaev, P.Ya.Polubarinova-Kochina, I.I.Krashin, R.N.Usmanov, V.M.Mironenko, V.M.Godberg, I.N.Tikhonov, J.H.Djumanov and many others. There are separate developments on mathematical modeling of the relationship of geofiltration processes according to the scheme formation ?transit zone ? unloading zone (K.Fletcher,E.Oran, F.M.Bochever, D.Anderson, L.S.Yazvin, A.M.Soifer, I.Ber, A.B.Vistelius, J.Kh.Djumanov and others) [Djumanov J.X. 2016, p.258]. With the advent of GIS technologies, it gave a personal impetus to the development of a mathematical modeling methodology for large regional hydrogeological objects, which allow integrating mathematical models of local parts of large hydrogeological objects on the basis of a unified computing system R.F.Tomlinson, A.M.Trofimov, A.D.Armand, A.M.Berland, A.V.Koshkarev, etc.

Modern software packages with a convenient interface on the one hand make an important contribution to the development of a geofiltration modeling methodology based on the widespread use of information technology [Mavlonov A.A.et al, 2010, p.35], and on the other hand, they are focused mainly on the use of factual, numerical information in the modeling process of weakly formalized processes in hydrogeology.

The object of our research was the Akhangaran groundwater field, which is a large industrial unit with intensification of agriculture, as well as densely populated, where industrial reproduction of water resources is established by designing water intake facilities using groundwater in the Tashkent region.

The main goal of these researches is to transfer the methodology for assessing groundwater resources by modeling geofiltration and mass transfer to the GIS basis and to introduce this model using the example of the Akhangaran river valley. To achieve the goal, the following tasks were solved. 
Formulation of the problem. These researches are a development of the methodology of mathematical modeling of hydrogeological processes. Of particular note are the merits of scientists from TUIT and the HYDROINGEO Institute: N.N. Khodjibaev, F.B. Abutaliev, U. U. Umarov, I.Kh. Khabibullaev, R.N. B. Bahramova, P. P. Nagevich, A. B. Alimbaev, J. Kh. Dzhumanova, I. N. Gracheva and others, who made a great contribution to the establishment, development and implementation of a methodology for modeling hydrogeological processes and it is worth noting that At this stage of research, five doctoral and ten master's theses have been prepared and defended [Hasanov A.S., 2005, p.212].

Recently, changing the mode of surface water flows in the Akhangaran Valley and increasing requirements for the rational use of water available against the background of a general shortage of water have led to the identification of a special class of problems in modeling geofiltration and geomigration processes of regional hydrogeological systems in disturbed natural and technogenic conditions [Saidmuradov Zh.Z.et al, 2008, p.116],[Umarov U. U., 1966, p.120],[Khabibullaev I., 1991, p.115].

Since in real time mode it is planned to solve a number of problems related to the schematization of the filtration area, the integration of geofiltration and salt transfer models, their finite-difference representations, the formalization of fuzzy parameters and characteristics on a fuzzydetermined basis, the synthesis of thematic layers in the process of solving applied problems, geographically dependent interpretation of data obtained from different horizons and thematic tasks, etc. [Zlotnik V.A. et al, 1985, p.296],[Usmanov R.K. et al, 2007, p.37]. In the main hydrogeological studies, where the use of mathematical modeling methods for geofiltration and geomigration is considered mandatory, these are the conditions of reclaimed territories and their mineralization, assessment of water resources and monitoring, protection of groundwater from pollution, i.e. modeling of hydrogeological processes in the conditions of uncertainty of the initial information.

To simulate mass transfer, as a rule, various equations of convective-diffusion type are used. Moreover, studies show [Anderson D. et al,1990, p.352],[Verigin N.N. et al, 1979, p. 156] that in real conditions the convective component of flows prevails. Usually, groundwater geofiltration is primarily modeled, and the result of this simulation is used to model mass transfer problems, etc. improvement of methods of hydrogeological models of groundwater fields based on modern geoinformation technologies [Djumanov J.X., 2016, p.258].

Substance transfer in a moving groundwater flow, i.e. geomigration, the processes of the substance transfer and heat by groundwater are determined, which are conditioned by the following basic phenomena as convection, diffusion, as well as by the physicochemical processes of the interaction of groundwater with mountain rocks[Abutaliev F.B. et al, 1980, p.15], [Verigin N.N.et al, 1979, p.235], [Fletcher K., 1991]:

Convective transfer by a filtered flow (forced convection) under the influence of a hydraulic gradient, proceeding at a speed $u=v / n$, where $v$ is the Darcy filtration rate and $n$ is porosity. The specific flow of substance (mass of substance moving in a unit volume of rock per unit time) due to convective transfer $\mathrm{IK}$ $=\mathrm{uC}$, where $\mathrm{C}$ is the content in the solution or concentration. 
Density convection associated with the presence of a vertical density gradient of solutions. Its speed is $v \rho=K z \Delta \rho$. In this expression, $v \rho$ is the vertical component of the filtration rate due to the density gradient, $\mathrm{Kz}$ is the filtration coefficient in the vertical direction, and $\Delta \rho=(\rho a-\rho b) / \rho b$, where the indices "a" and " $b$ " correspond above and below the underlying water. In this case, movement can occur only when the mineralization of a denser overlying solution is $2-5 \mathrm{~g} / \mathrm{l}$ higher than that of a less dense solution below it. Specific flow $\mathrm{l} \rho=\mathrm{v} \rho \mathrm{C}$.

Diffusion transfer obeying the Fick law IDf $=\mathrm{DM} \partial C \partial \mathrm{I}$, where DM is the molecular diffusion coefficient in a water-saturated medium, and I is the distance in the direction of the concentration gradient.

Hydrodynamic dispersion controlled by the dispersion coefficient $D v=\delta v$. The dispersion coefficient $\delta$ used here is determined by the size and the void structure of the rock, and the specific substance flow due to the dispersion I_Dp=D_v $\partial C \partial \mathrm{O}$. Since transfer due to diffusion and dispersion are physical analogues, the concept of the total dispersion coefficient $D=D M+D v$ is introduced. In this case, 【I_Df+I】_Dp=DaColare defined together.

Given the salinization of aquifers of molecular diffusion and dispersion in order to study the movement of fresh groundwater and the migration of their pollutants, as well as the relationship with surface water, it is necessary to solve the following system of equations [Abutaliev F.B. et al, 1980, p.15], [Anderson D.et al, 1990], [Verigin N.N. 1979], [Samarsky A.A. 1983]):

$$
\begin{aligned}
& \left\{\begin{array}{c}
\mu \frac{\partial \mathrm{H}}{\partial \mathrm{t}}=\frac{\partial}{\partial \mathrm{x}}\left(\mathrm{km} \frac{\partial \mathrm{H}}{\partial \mathrm{x}}\right)+\frac{\partial}{\partial \mathrm{y}}\left(\mathrm{km} \frac{\partial \mathrm{H}}{\partial \mathrm{y}}\right)+\mathrm{W}_{\Pi}-\mathrm{W}_{\mathrm{o}} \\
\mu \frac{\partial(\mathrm{mC})}{\partial \mathrm{t}}=\frac{\partial}{\partial \mathrm{x}}\left(\mathrm{Dm} \frac{\partial \mathrm{C}}{\partial \mathrm{x}}-\mathrm{mv}_{\mathrm{x}} \mathrm{C}\right)+\frac{\partial}{\partial \mathrm{y}}\left(\mathrm{Dm} \frac{\partial \mathrm{C}}{\partial \mathrm{y}}-\mathrm{mv}_{\mathrm{y}} \mathrm{C}\right)+\mathrm{W}_{\Pi} \mathrm{C}_{\Pi}-\mathrm{W}_{\mathrm{o}} \mathrm{C}_{\mathrm{o}}
\end{array}\right. \\
& \text { with boundary conditions }\left\{\begin{array}{l}
H(x, y, t)=F_{1}(x, y, t) ; x, y \in \Gamma_{1} ; t>t_{0} \\
C(x, y, t)=F_{2}(x, y, t) ; x, y \in \Gamma_{2} ; t>t_{0}
\end{array}\right. \\
& \left\{\begin{array}{c}
-\mathrm{km} \frac{\partial \mathrm{H}}{\partial \mathrm{n}}=\mathrm{F}_{3}(\mathrm{x}, \mathrm{y}, \mathrm{t}) ; \mathrm{x}, \mathrm{y} \in \Gamma_{3} ; \quad \mathrm{t}>\mathrm{t}_{0} ; \\
-\mathrm{D}_{\mathrm{n}} \mathrm{m} \frac{\partial \mathrm{C}}{\partial \mathrm{n}}+\mathrm{mv}_{\mathrm{n}} \mathrm{C}=\mathrm{mv}_{\mathrm{n}} \mathrm{C} ; \quad \mathrm{x}, \mathrm{y} \in \Gamma_{4} ; \mathrm{t}>\mathrm{t}_{0} ;
\end{array}\right. \\
& \left\{\begin{array}{c}
-\mathrm{km} \frac{\partial \mathrm{H}}{\partial \mathrm{n}}=\mathrm{km} \frac{\mathrm{H}_{\mathrm{B}-\mathrm{H}}}{\phi} ; \mathrm{x}, \mathrm{y} \in \Gamma_{5} ; \mathrm{t}>\mathrm{t}_{0} ; \\
-\mathrm{D}_{\mathrm{n}} \mathrm{m} \frac{\partial \mathrm{C}}{\partial \mathrm{n}}+\mathrm{mv}_{\mathrm{n}} \mathrm{C}=\mathrm{mv}_{\mathrm{n}} \mathrm{C} ; \mathrm{x}, \mathrm{y} \in \Gamma_{6} ; \mathrm{t}>\mathrm{t}_{0}
\end{array}\right.
\end{aligned}
$$


and initial conditions (Cauchy problem) $\left\{\begin{array}{l}\mathrm{H}\left(\mathrm{x}, \mathrm{y}, \mathrm{t}_{0}\right)=\varphi(\mathrm{x}, \mathrm{y}) ; \mathrm{t} \geq \mathrm{t}_{0} \\ \mathrm{C}\left(\mathrm{x}, \mathrm{y}, \mathrm{t}_{0}\right)=\psi(\mathrm{x}, \mathrm{y}) ; \mathrm{t} \geq \mathrm{t}_{0}\end{array}\right.$

where, $\varphi(\mathrm{x}, \mathrm{y}), \psi(\mathrm{x}, \mathrm{y})$ are the given functions, $\Gamma=\Gamma_{1}+\Gamma_{2}+\Gamma_{3}+\Gamma_{4}+\Gamma_{5}+\Gamma_{6}$ boundary.

In the equations of system (1)-(5), $\mu$ is free water loss; $H(x, y, t)$ - groundwater level in absolute grades, $H_{B}(x, y, t)$ - water level in the channel, in $\mathrm{m} ; \Phi(\mathrm{x}, \mathrm{y}, \mathrm{t})$ is the filtering resistance of the channel, $\mathrm{m}=\mathrm{H}-\mathrm{b}(\mathrm{x}, \mathrm{y})$ is the power of the aquifer; $k(x, y)$ is the filtration coefficient $\mathrm{m} /$ day; $\mathrm{W}_{\mathrm{n}}=\sum_{i=1}^{n} W_{i}^{n}(x, y, t)$ is the intensity of various groundwater supply factors (including pollutants) with a concentration of $C_{n}(x, y, t), \quad m /$ day; $W_{0}=$ $\sum_{i=1}^{n} W_{i}^{0}(x, y, t)$ - groundwater flow rate (withdrawal, drainage, evaporation) from a certain concentration of $C_{0}(x, y, t), m$ / day; $D_{x}=D_{m}+\lambda_{x}\left|v_{x}\right|, \quad D_{y}=D_{m}+\lambda_{y}\left|v_{y}\right|$-component convective diffusion coefficients; $D_{m}$ is the

$$
\begin{gathered}
\mathrm{H}^{*}=\frac{\mathrm{H}}{\mathrm{H}_{0}} ; \mathrm{K}=\frac{\mathrm{K}}{\mathrm{T}_{0}} ; \mathrm{m}^{*}=\frac{\mathrm{m}}{\mathrm{H}_{0}} ; \mathrm{C}^{*}=\frac{\mathrm{C}}{\mathrm{C}_{0}} ; \mathrm{D}^{*}=\frac{\mathrm{D}}{\mathrm{H}_{0} \mathrm{~T}_{0}} ; \phi^{*}=\frac{\phi}{\mathrm{R}_{0}} ; \\
\xi=\frac{\mathrm{X}}{\mathrm{L}} ; \eta=\frac{\mathrm{Y}}{\mathrm{L}} ; \tau=\frac{\mathrm{H}_{0} \mathrm{~T}_{0}}{\mu \mathrm{L}^{2}} \mathrm{t} ; \mathrm{W}_{\Pi}^{*}=\frac{\mu \mathrm{L}^{2}}{\mathrm{H}_{0}^{2}} \mathrm{~W}_{\Pi} ; \mathrm{W}_{0}^{*}=\frac{\mu \mathrm{L}^{2}}{\mathrm{H}_{0}^{2} \mathrm{~T}_{0}} \mathrm{~W}_{0}^{*},
\end{gathered}
$$

whereHo, Co, Do, RoTo are some characteristic values of the pressure function, concentration, convective diffusion and filtration coefficient, $L$ is the maximum extent in the region $\mathrm{G}$. Since in what follows we deal with equations in dimensionless form, $\left({ }^{*}\right)$

$$
\left\{\begin{array}{c}
\frac{\partial \mathrm{H}}{\partial \tau}=\frac{\partial}{\partial \xi}\left(\mathrm{km} \frac{\partial \mathrm{H}}{\partial \xi}\right)+\frac{\partial}{\partial \eta}\left(\mathrm{km} \frac{\partial \mathrm{H}}{\partial \eta}\right)+\mathrm{W}_{\Pi}-\mathrm{W}_{0} \\
\frac{\partial(\mathrm{mC})}{\partial \tau}=\frac{\partial}{\partial \xi}\left(\mathrm{D}_{\xi} \mathrm{m} \frac{\partial \mathrm{C}}{\partial \xi}-\mathrm{mv}_{\xi} \mathrm{C}_{\xi}\right)+\frac{\partial}{\partial \eta}\left(\mathrm{D}_{\eta} \mathrm{m} \frac{\partial \mathrm{C}}{\partial \eta}-\mathrm{mv}_{\eta} \mathrm{C}_{\eta}\right)+\mathrm{W}_{\Pi} \mathrm{C}_{\Pi}-\mathrm{W}_{\mathrm{o}} \mathrm{C}_{\mathrm{o}}
\end{array}\right.
$$


Indices $\mathrm{i}, \mathrm{j}, \tau$ are introduced and steps $\Delta \xi, \Delta$ nand $\Delta \tau$ along the $\mathrm{x}, \mathrm{y}, \mathrm{t}$ axes, respectively. Parts of the boundary with a condition of the first kind can be arbitrary, but with conditions of the second or third kind, they are taken as stepped lines with segments parallel to the coordinate axes. In the rectangle $\xi_{\mathrm{i}-0.5} \leq \xi \leq \xi_{\mathrm{i}+0.5}, \tau_{\mathrm{j}} \leq \tau \leq \tau_{\mathrm{j}+1}$, the balance equation for system is written (6).

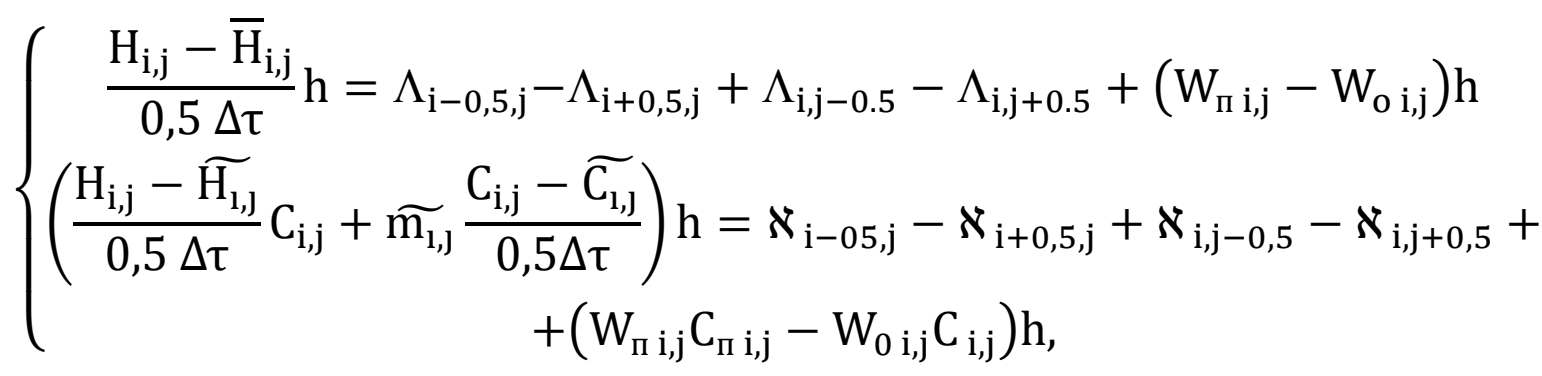

$$
\text { where, } \Lambda_{\mathrm{i}-0,5, j}=-(\mathrm{km})_{\mathrm{i}-0,5, \mathrm{j}} \frac{\mathrm{H}_{\mathrm{i}, \mathrm{j}}-\mathrm{H}_{\mathrm{i}-1, \mathrm{j}}}{\Delta \mathrm{l}} ; \Lambda_{\mathrm{i}+0,5, \mathrm{j}}=-(\mathrm{km})_{\mathrm{i}+0,5, \mathrm{j}} \frac{\mathrm{H}_{\mathrm{i}+1, \mathrm{j}}-\mathrm{H}_{\mathrm{i}, \mathrm{j}}}{\Delta \mathrm{l}}
$$

$$
\begin{aligned}
\aleph_{\mathrm{i}-0.5, \mathrm{j}} & =-\left[(\mathrm{Dm})_{\mathrm{i}-0.5, \mathrm{j}} \frac{\mathrm{C}_{\mathrm{i}, \mathrm{j}}-\mathrm{C}_{\mathrm{i}-1, \mathrm{j}}}{\Delta \mathrm{l}}-(\Lambda)_{\mathrm{i}-0.5, \mathrm{j}} \mathrm{CL}_{\mathrm{i}}\right] \\
\aleph_{i+0.5, j} & =-\left[(D m)_{i+0.5, j} \frac{C_{i+1, j}-C_{i, j}}{\Delta l}-(\Lambda)_{i+0.5, j} C R_{i}\right]
\end{aligned}
$$

$(m v)_{i, j \pm 0,5}$ and

the values of the concentrations of $\mathrm{CL}_{\mathrm{i}}$ and $\mathrm{CR}_{\mathrm{i}}$ at the flow points are calculated through the values of the concentrations in the neighboring nodes depending on the direction

$$
\aleph_{i, j \pm 0.5} \bar{h}_{i, j}=h_{i, j}^{k+1}, \bar{C}_{i, j}=C_{i, j}^{k+1}
$$

of the velocity between these nodes, using the countercurrent method [Anderson D.,1990],[Verigin N.N. et al, 1979], [Djumanov J.X.,2016, p.258].

$$
C R_{i}=\left\{\begin{array}{l}
C_{i}, \text { if }-(m \vartheta)_{i+0.5}>0 \\
C_{i+1}, \text { if }-(m \vartheta)_{i+0.5}<0,
\end{array} C L_{i}= \begin{cases}C_{i-1}, & \text { if }-(m \vartheta)_{i-0.5}>0 \\
C_{i}, & \text { if }-(m \vartheta)_{i+0.5}<0 .\end{cases}\right.
$$

After some transformations the standard system is taken

$$
\begin{gathered}
\left\{\begin{array}{l}
a_{i, j} H_{i-1, j}-b_{i, j} H_{i, j}-c_{i, j} H_{i+1, j}=-d_{i, j} \\
a_{i, j}^{T} C_{i-1, j}-b_{i, j}^{T} C_{i, j}-c_{i, j}^{I} C_{i+1, j}=-d_{i, j}^{I}
\end{array}\right. \\
\text { where, } a_{i, j}=\Lambda_{i-0,5, j}, \quad c_{i, j,}=\Lambda_{i+0,5, j}, \quad b_{i, j}=a_{i, j}+c_{i, j}+\gamma, \quad \gamma=\mu \frac{2 l^{2}}{\Delta t},
\end{gathered}
$$




$$
\begin{aligned}
& d_{i, j}=\gamma \bar{h}_{i, j}+l^{2}\left(W_{\Pi i, j}-W_{0 i, j}\right)+\varphi_{i, j}, \quad \varphi_{i, j}=l\left[\Lambda_{i, j+0,5}-\Lambda_{i, j-0,5}\right], \\
& a_{i, j}^{\prime}=\aleph_{i-0,5, j}+S_{i, j}^{1}, \quad c_{i, j}^{\prime}=\Lambda_{i+0,5, j}+S_{i, j}^{2}, \\
& b_{i, j}^{\prime}=a_{i, j}^{\prime}+c_{i, j}^{\prime}+\gamma m_{i, j}+l^{2} W_{\Pi i, j}+\varphi_{i, j} \\
& S_{i, j}^{1}=\left\{\begin{array}{ll}
l(\Lambda)_{i-0,5, j} & \text { If }(\Lambda)_{i-0,5, j}>0 \\
0, & \text { If }(\Lambda)_{i-0,5, j}<0
\end{array}, S_{i, j}^{2}=\left\{\begin{array}{cc}
l(\Lambda)_{i+0.5, j}, \text { If }(\Lambda)_{i+0.5, j}<0, \\
0, & \text { If }(\Lambda)_{i+0,5, j}>0,
\end{array}\right.\right. \\
& d_{i, j}^{\prime}=\gamma m_{i, j}^{\prime} \widetilde{C_{l, j}}+l^{2} W_{\pi i, j} C_{\pi i, j}+\psi_{i, j} \\
& \psi_{i, j}=\left[(D m)_{i, j-0.5}+P_{1 i, j}\right] C_{i, j-1} \\
& +\left[P_{2 i, j}-P_{3 i, j}-(D m)_{i, j-0.5}--(D m)_{i, j+0.5}\right] C_{i, j} \\
& +\left[(D m)_{i, j+0.5}-P_{4 i, j}\right] C_{i, j+1} \text {, } \\
& P_{1 i, j}=\left\{\begin{array}{cc}
l(\Lambda)_{i, j-0.5}, & \text { If }(\Lambda)_{i, j-o .5}>o \\
0, & \text { If }(\Lambda)_{i, j-o .5}<o
\end{array}, \quad P_{2 i, j}=\left\{\begin{array}{c}
l(\Lambda)_{i, j-0.5}, \text { If }(\Lambda)_{i, j-o .5}<o \\
0, \quad \text { If }(m v)_{i, j-o .5}>o
\end{array}\right.\right. \\
& P_{3 i, j}=\left\{\begin{array}{c}
l(\Lambda)_{i, j-0.5}, \quad \text { If }(\Lambda)_{i, j+o .5}>o \\
0, \quad \text { If }(\Lambda)_{i, j+o .5}<o
\end{array}, P_{4 i, j}=\left\{\begin{array}{c}
l(\Lambda)_{i, j-0.5}, \text { If }(\Lambda)_{i, j+o .5}<o \\
0, \quad \text { If }(\Lambda)_{i, j+o .5}>o
\end{array}\right.\right.
\end{aligned}
$$

the approximation of the boundary conditions of the second and third kind is condidered separately. Using the balance method, the difference approximation of the boundary conditions (BC) (2) and (4) is given in mind.

$\left\{\begin{array}{l}H_{0, j}=\varkappa_{1, j} H_{1, j}+v_{1, j} \\ C_{0, j}=\varkappa_{1, j}^{\prime} C_{1, j}+v_{1, j}^{\prime}\end{array}\left\{\begin{array}{l}H_{N, j}=\varkappa_{2, j} H_{N-1, j}+v_{2, j} \\ C_{N, j}=\varkappa_{2, j}^{\prime} C_{N-1, j}+v_{2, j}^{\prime}\end{array}\right.\right.$ 


$$
\begin{aligned}
& \varkappa_{1, j}=\left\{\begin{array}{cc}
0, & \text { If } B C \text { I kind } \\
\frac{C_{0, j}}{C_{0, j}+\breve{\gamma}}, & \text { If } B C \text { II kind } \\
\frac{C_{0, j}}{C_{0, j}+\breve{\gamma}+\gamma_{1}}, & \text { If } B C \text { III kind }
\end{array}\right.
\end{aligned}
$$

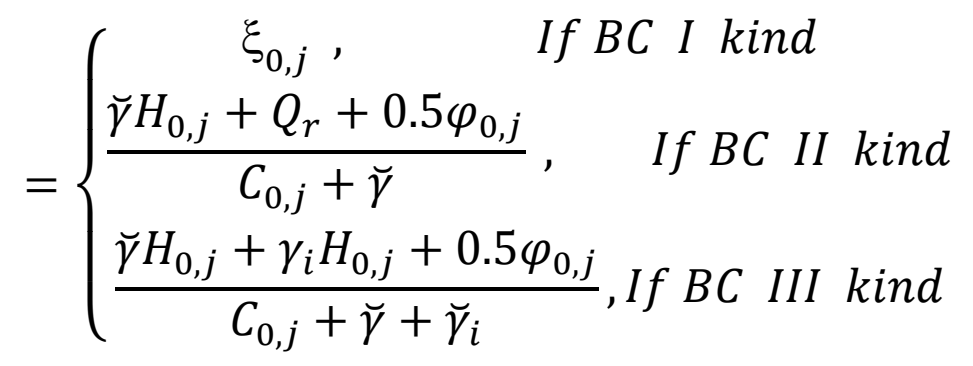

$$
\begin{aligned}
& \mathcal{H}_{1, j}^{\prime}=\left\{\begin{array}{cc}
0, \quad \text { If BC I kind } \\
\frac{\breve{C}_{0, j}}{\breve{C}_{0, j}+\breve{\gamma} \widetilde{m}_{0, j}+\tau_{i}+0.5 \varphi_{0, j}}, \text { If BC II kind } \\
\frac{C_{0, j}}{\breve{C}_{0, j}+\breve{\gamma} \widetilde{m}_{0, j}+Q_{1}+0.5 \varphi_{0, j}}, \quad \text { If BC III kind }
\end{array}\right. \\
& v_{1, j}^{\prime}=\left\{\begin{array}{l}
\xi_{0, j} \text { If BC I kind } \\
\frac{\widetilde{\gamma m}_{0, j}+\breve{C}_{0, j}+\tau_{1} C_{1}+0.5 \varphi_{x, j}}{\breve{C}_{0, j}+\breve{\gamma} \widetilde{m}_{0, j}+\tau_{1}+0.5 \varphi_{0, j}} \text { If BC II kind } \\
\frac{\breve{\gamma} \widetilde{m}_{0, j}+C_{0, j}+\tau_{1} C_{b}+0.5 \varphi_{x, j}}{\breve{C}_{0, j}+\breve{\gamma} \widetilde{m}_{0, j}+Q_{1}+0.5 \varphi_{0, j}} \text { If BC III kind }
\end{array}\right. \\
& \varkappa_{2, j}=\left\{\begin{array}{cc}
0, & \text { If BC I kind } \\
\frac{a_{N, j}}{a_{N, j}+\breve{\gamma}}, & \text { If BC II kind } \\
\frac{a_{N, y}}{\breve{a}_{N, j}+\breve{\gamma}+\breve{\gamma}_{2}}, & \text { If BC III kind }
\end{array} v_{2, j}\right. \\
& =\left\{\begin{array}{c}
\frac{\xi_{N, j}, \quad \text { If } B C \text { I kind }}{\frac{\breve{\gamma} H_{N, j}+Q_{r}+0.5 \varphi_{N, j}}{a_{n, j}+\breve{\gamma}},} \quad \text { If } B C \text { II kind } \\
\frac{\breve{\gamma} H_{N, j}+\gamma_{2} H_{\mathrm{B}}+0.5 \varphi_{N, j}}{a_{N, j}+\breve{\gamma}+\breve{\gamma}_{2}}, \text { If BC III kind }
\end{array}\right.
\end{aligned}
$$




$$
\begin{aligned}
& \varkappa_{2, j}^{\prime}=\left\{\begin{array}{c}
0, \quad \text { If BC I kind } \\
\frac{\breve{a}_{N, j}}{\breve{a}_{N, j}+\breve{\gamma} \widetilde{m}_{N, j}+\tau_{i}+0.5 \varphi_{N, j}} \text {, If BC II kind } \\
\frac{C_{0, j}}{\breve{a}_{N, j}+\breve{\gamma} \widetilde{m}_{N, j}+\breve{Q}_{1}+0.5 \varphi_{N, j},} \text { If BC III kind }
\end{array}\right. \\
& =\left\{\begin{array}{c}
\xi_{N, j}, \quad \text { If BC I kind } \\
\frac{\breve{\gamma} \widetilde{m}_{N, j}+\breve{C}_{N, j}+q_{2} C_{\tau}+0.5 \psi_{N, j},}{\breve{C}_{N, j}+\breve{\gamma} \widetilde{m}_{N, j}+q_{2}+0.5 \varphi_{N, j}} \text { If BC II kind } \\
\frac{\gamma \widetilde{m}_{N, j}+\breve{C}_{N, j}+q_{2} C_{b}+0.5 \psi_{N, j}}{\breve{C}_{n, j}+\breve{\gamma} \widetilde{m}_{n, j}+q_{2}+0.5 \varphi_{n, j}}, \text { If BC III kind }
\end{array}\right.
\end{aligned}
$$

To provide a positive solution to problem (8), certain conditions are imposed on the time $\mu \frac{\Delta x^{2}}{T_{o} H_{o}}$. To solve the system of equations (8), step $\Delta$ t. In [Verigin N.N.et al, 1963], [Djumanov we apply the sweep method, according to J.X.,2016, p.28], this condition has the $=$ which the solution if found in the form

$$
\left\{\begin{array}{l}
H_{i, j}=\alpha_{i+1, j} H_{i+1, j}+\beta_{i+1, j} \\
C_{i, j}=\alpha_{i+1, j}^{\prime} C_{i+1, j}+\beta_{i+1, j}^{\prime}
\end{array}\right.
$$

For $\mathrm{i}=\mathrm{i}-1$, we insert equation (10) into (8) after some algebraic transformations, the equation

where, $\quad\left\{\begin{aligned} \alpha_{i+1, j} & =\frac{\mathrm{c}_{i, j}}{b_{i+1, j}-\mathrm{c}_{i, j} \alpha_{i, j}} \\ \alpha_{i+1, j}^{\prime} & =\frac{c_{i, j}^{\prime}}{b_{i, j}^{\prime}-a_{i, j}^{\prime} \alpha_{i 1, j}^{\prime}}\end{aligned}\right.$

To determine $\alpha_{i, j}$, and $\beta_{i, j} ; \quad \alpha_{i, j}^{\prime}$ and $\beta_{i, j}^{\prime}$ the boundary conditionsfor $\xi=0$ are used.

$$
\left\{\begin{array}{l}
\alpha_{1, j}=\varkappa_{1, j} \\
\alpha_{1, j}^{\prime}=\varkappa_{2, j}^{\prime}
\end{array}, \quad\left\{\begin{array}{l}
\beta_{1, j}=v_{1, j} \\
\beta_{1, j}^{\prime}=v_{2, j}^{\prime}
\end{array},\right.\right.
$$

for $\alpha_{i+1, j}$, and $\beta_{i+1, j} ; \quad \alpha_{i+1, j}^{\prime}$ and $\quad \beta_{i+1, j}^{\prime}$ are obtained.

$$
\left\{\begin{array}{l}
\beta_{i+1, j}=\frac{a_{i, j} \beta_{i, j}-d_{i, j}}{b_{i+1, j}-c_{i, j} \alpha_{i, j}} \\
\beta_{i+1, j}^{\prime}=\frac{a_{i, j}^{\prime} \beta_{i, j}^{\prime}-d_{i, j}^{\prime}}{b_{i, j}^{\prime}-a_{i, j}^{\prime} \alpha_{i 1, j}^{\prime}}
\end{array}\right.
$$

From formulas (9) and (10) for $\mathrm{i}=0$ it is found that 
Finding $\alpha_{1, j}$, and $\beta_{1, j} ; \alpha_{1, j}^{\prime}$ and $\beta_{1, j}^{\prime}$ and passing from $\mathrm{i}=0$ to $\mathrm{i}=\mathrm{i}+1$ by formula (10), all values of $\alpha_{i, j}$, and $\beta_{i, j} ; \alpha_{i, j}^{\prime}$ and $\beta_{i, j}^{\prime}$ for all $\mathrm{i}, \mathrm{j}=1,2, \ldots \mathrm{N}$ using the direct sweep method are determined.the coefficients of the equations is found.
Calculations by formula (10) are carried out by passing from $\mathrm{i}=\mathrm{i}+1$ to $\mathrm{i}$, i.e., we use the inverse sweep method, and to begin these calculations, it is needed to know $\mathrm{H}_{\mathrm{N}, \mathrm{j}}$ and $\mathrm{C}_{\mathrm{N}, \mathrm{j}}$. To determine these values in the system of equations (10), the value $\mathrm{i}=\mathrm{N}-1$, we obtain the following relationship:

$$
\left\{\begin{array}{l}
H_{N-1, j}=\alpha_{N, j} H_{N, j}+\beta_{N, j} \\
C_{N-1, j}=\alpha_{N, j}^{\prime} C_{N, j}+\beta_{N, j}^{\prime}
\end{array}\right.
$$

Solving it together with system (8) and after performing some algebraic operations, we obtain the values of $\mathrm{H}_{\mathrm{N}, \mathrm{j}}$ and $\mathrm{C}_{\mathrm{N}, \mathrm{j}}$, in the case of boundary conditions of the first kind.

$$
H_{N, j}=\frac{v_{2, j}+\varkappa_{2, j} \beta_{N, j}}{1-\varkappa_{2, j} \alpha_{N, j}}, \quad C_{N, j}=\frac{v_{N, j}^{\prime}+\varkappa_{N, j}^{\prime} \beta_{N, j}^{\prime}}{1-\varkappa_{2, j} \alpha_{N, j}},
$$

in case of boundary conditions of the second kind,

$$
C_{N, j}=\frac{a_{N, j}^{\prime} \beta_{N, j}^{\prime}+\left(P_{1}^{\prime}+\gamma m_{N, j}^{\prime}\right) \bar{C}_{N, j}^{\prime}+P_{2} C_{\Pi}+\mathrm{C} C_{N, j}}{\left(1-\mathcal{H}_{2, j} \alpha_{N, j}\right)\left(a_{N, j}^{\prime}+P_{1}^{\prime}\right)+\gamma m_{N, j}^{\prime}+P_{2}^{\prime}+S S_{N, j}}
$$

in case of boundary conditions of the third kind,

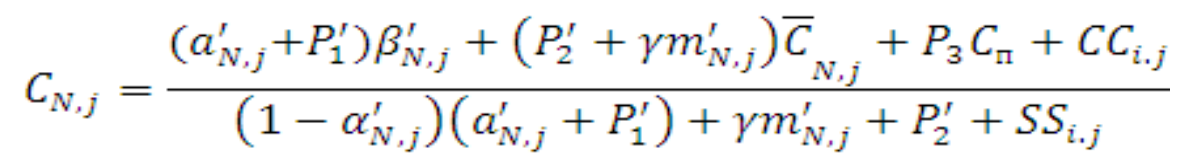

Thus, all values of $\mathrm{HN}$,jand $\mathrm{CN}$,jare determined over the entire area of geofiltration and geomigration. Therefore, using the above schemes, it is possible to study the processes of groundwater movement and the relationship with surface water and changes in the concentration of fresh water pollution, both in space and in time.

The developed mathematical model has been introduced to solve national economic problems in certain regions of the Republic of Uzbekistan; for this, a method for calculating individual articles of groundwater balance has been carried out. At a specific object, using the example of the Akhangaran underground water fields for a certain period of time, a balance is determined (annual average, seasonal, average long-term, etc.). The balance consists of water inflow (infiltration, groundwater inflow into the balance circuit, overflow from other aquifers) and water flow (groundwater outflow, withdrawal, wedging hidden in rivers, drains and open - spring; total evaporation). In the research area, a significant amount of infiltration occurs not only from water bodies, but also from the irrigation network and during irrigation of land (and plantations) [Saidmuradov Zh.Z.et al, 
2008, p.116], [Mavlonov A.A.et al, 2011, p.269],[Mirzaev S.Sh., 1974].

Typization and schematization. Typization is the allocation of the same type of sites according to hydrodynamic features and possible design schemes. They are distinguished by the generality of the flow structure, bedding conditions and the hydraulic state of aquifers, by the generality of the reservoir structure and the boundary conditions acting on them.

Schematization - identifying the main factors; determining the most reliable scheme of the structure of the reservoir and the calculated values of the parameters; - simplification of filtration and replacement of spatial by planned or plane-vertical; - simplification of the forms of borders and laws of change in them levels and costs of flows. In schematization takes into account the physical and theoretical foundations of the processes under study. First, the type of filtration, the flow dimension, and the size of the studied region are estimated, then the structure composition of the studied complex, the internal and external boundaries, and boundary conditions are established.

For the Akhangaran underground water fields as a whole, the physical and geographical situation of the region, taking into account the foregoing, is characterized by the following main factors affecting the formation of hydrogeological conditions. In the mountainous and foothill parts of the region, a significant amount of precipitation falls, supplying a dense hydrographic network and fractured waters of Paleozoic rocks. Submitting to the general slope of the terrain, the flows of surface and groundwater from the mountains enter the foothills, being consumed by absorption into friable fragments of the foothill plume, large sais and partly by evaporation. The relief structure of the described area and a significant slope within most of it (0.07-0.05) favor the accumulation of groundwater due to the infiltration of atmospheric precipitation and surface water and contribute to good groundwater flow within the Ahangaran pool [Saidmuradov Zh.Z. et al, 2008, p.116].

The water content of the pools is completely dependent on their altitude and the amount of precipitation. The command position belongs to the catchment pool of the Akhangaran River, located at an altitude of 3.0-4.5 thousand $m$ above sea level. The area of work, according to hydrological zoning, is fully included in the Pristashkent artesian pool and is located on the border of the mountainfolding and platform areas. The mountainous part of the area, composed of Paleozoic rocks, is part of the Chatkalo-Kuraminsky group of fractured water pools. A plain covered with a thick cover of the Pristashkent artesian pool [Saidmuradov Zh.Z.et al, 2008, p.116],[Rakhmatullayev Sh. et al, 2012, p.67].

The hydrological type of mode is traced in the floodplain and the first floodplain terrace of the river of Ahangaran region. The annual amplitude is from 0.5 to $2.5 \mathrm{~m}$. The mixed (hydrological-irrigation) type of mode is traced in the articulation band of the floodplain with I and II floodplain, in the flood zone, its width varies from hundreds of meters to $1.0 \mathrm{~km}$. Here the annual amplitude of the level fluctuation is 2-3 $\mathrm{m}$. A large area of the valley is characterized by the irrigation type of mode (more correctly, the infiltrationstock type of mode).

Particular attention in the schematization of hydrogeological conditions was given to the geofiltration characteristics of the main aquifer - a complex of Quaternary sediments by territory, area and thickness of aquifers. Hydrogeological zoning was carried out according to geostructural, geomorphological and lithological facies. Technogenic objects affecting the hydrodynamic state of groundwater are diverse. For the purposeful analysis, assessment and identification of 
manifestations of the impact of technogenic objects on the hydrodynamic state of groundwater and the consequences of their impact on the ecological and hydrogeological situation in the territories, the need arises for their typification [Bindeman N.A.,1963],[Umarov U. U., 1978].

\section{RESULTS}

Conducting experiments. In general, geomigration modeling includes several successive interconnected steps: 1) Geofiltration calculation, which determines the water level, and then the speed of movement of solutions and the components contained in them in the direction of the coordinate axes at time $\tau$ k. 2) Independent calculation of the dispersion component of mass transfer by $\tau \mathrm{k}$ for $\Delta \tau$. 3) Independent calculation of the action of effluents of a substance, including the calculation of interactions in the water - rock system, at the same time step. As a result of calculations, in accordance with geofiltration, the distribution in the calculation nodes of the current levels, as well as the compositions of other calculated parameters of the liquid phases, is determined, after which all the calculations for the next time step, etc., are repeated until a specified final point in time is reached.

Based on the developed modeling programs for estimating forecast resources taking into account changes in water management conditions, the results on the current state of groundwater fields were obtained and recommendations were made on the use of groundwater for irrigation in order to increase the water supply of the valley (Fig. 1). Unlike the traditional presentation, the electronic version of the results is presented by means of a geographic information system (GIS), and the possibility of developing the contents of an electronic map in a semi-automatic mode has been implemented [Djumanov J.X., 2016, p.258],[Zlotnik V.A. et al, 1985].
It should be noted a natural increase in the salinity and pollution of groundwater from the floodplain to the sides of the valley. The location within the valley of large industrial facilities from whose territory sewage contaminated water comes, as well as irrigated agriculture with the use of fertilizers, pesticides, herbicides create an unfavorable sanitary condition of groundwater. Deterioration of surface water and groundwater in the river valley. Ahangaran has been observed since 1967. An increased content of nitrite phenols was found in the water intakes of Kibray, Yuzhny, Sergeli, Yangiyul. The upper part of the aquifer outside the floodplain is contaminated with nitrates (0.5-1.0 MPC). Three types of groundwater modes are distinguished in the Ahangaran valley: hydrological, irrigation, and mixed [Saidmuradov Zh.Z. et al, 2008, p.116],[Mirzaev S.Sh., 1974].

Taking into account the level, area and specific features of the manifestation of the impact and their consequences, technogenic objects are divided into:

- irrigation systems;

- systematic reclamation drainage systems;

- reservoirs and large hydraulic units;

- large irrigation canals;

- Groundwater intakes.

The structural block diagram of the model is based on separate maps of the depths of the soles of the assigned layers relative to the surface of the relief (Fig. 1). The geometry of the terrain model is determined by the coordinate system in which the digital surface model is created. The choice of a local rectangular coordinate system makes it possible to simplify the combination of terrain models and urban objects that are created in a rectangular coordinate system. To enter the absolute elevation of the earth's surface into the model, we used the shp file of relief contour lines prepared in ArcGIS in the GaussKrueger metric coordinate system (Pulkovo, 
1942), from which, by interpolation, the absolute elevation marks were determined in each cell of the model grid [Djumanov J.X., 2016, p.28],[Yurkov V.Yu.,2006, p.96]. To specify the roof and sole of each selected layer in the model, .xls-files were used that

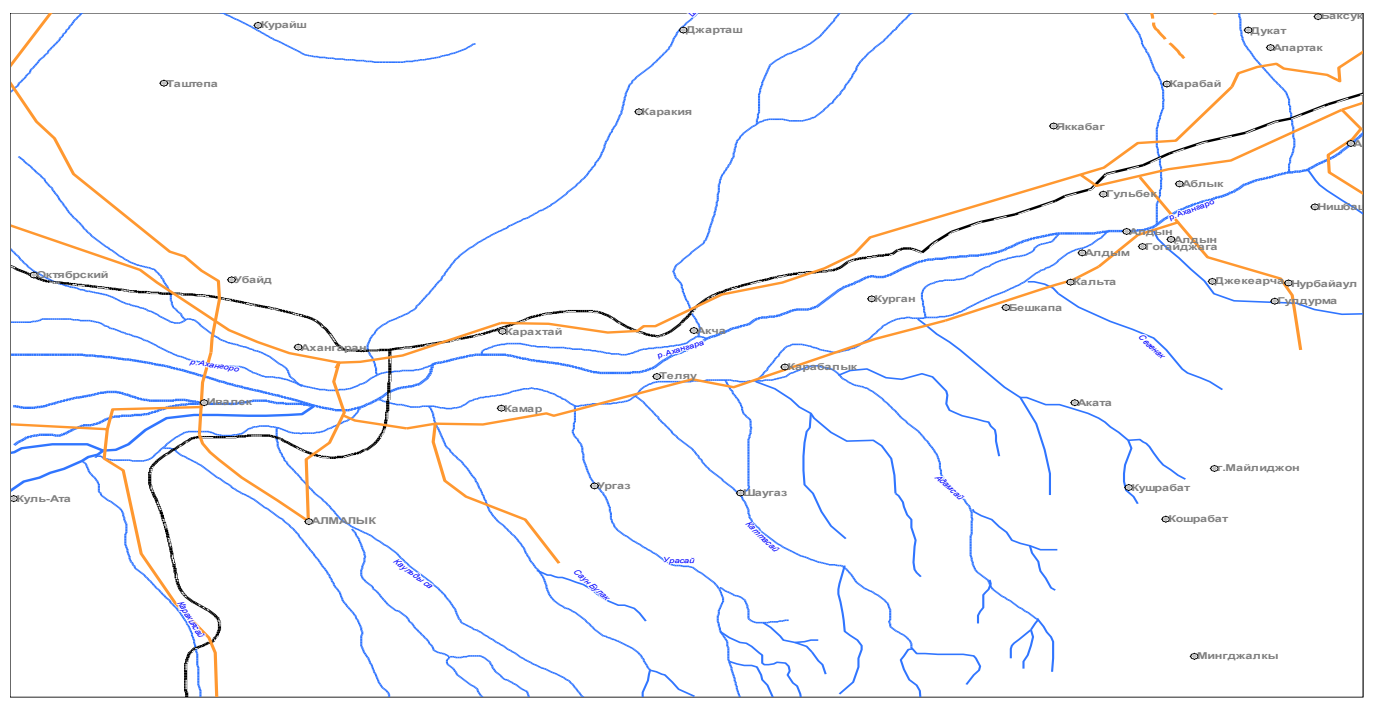

Fig. 1. Schematic map of the actual material of road networks and water intakes of the research object contained the absolute marks of the roof and the sole of each layer at anchor points with known coordinates 


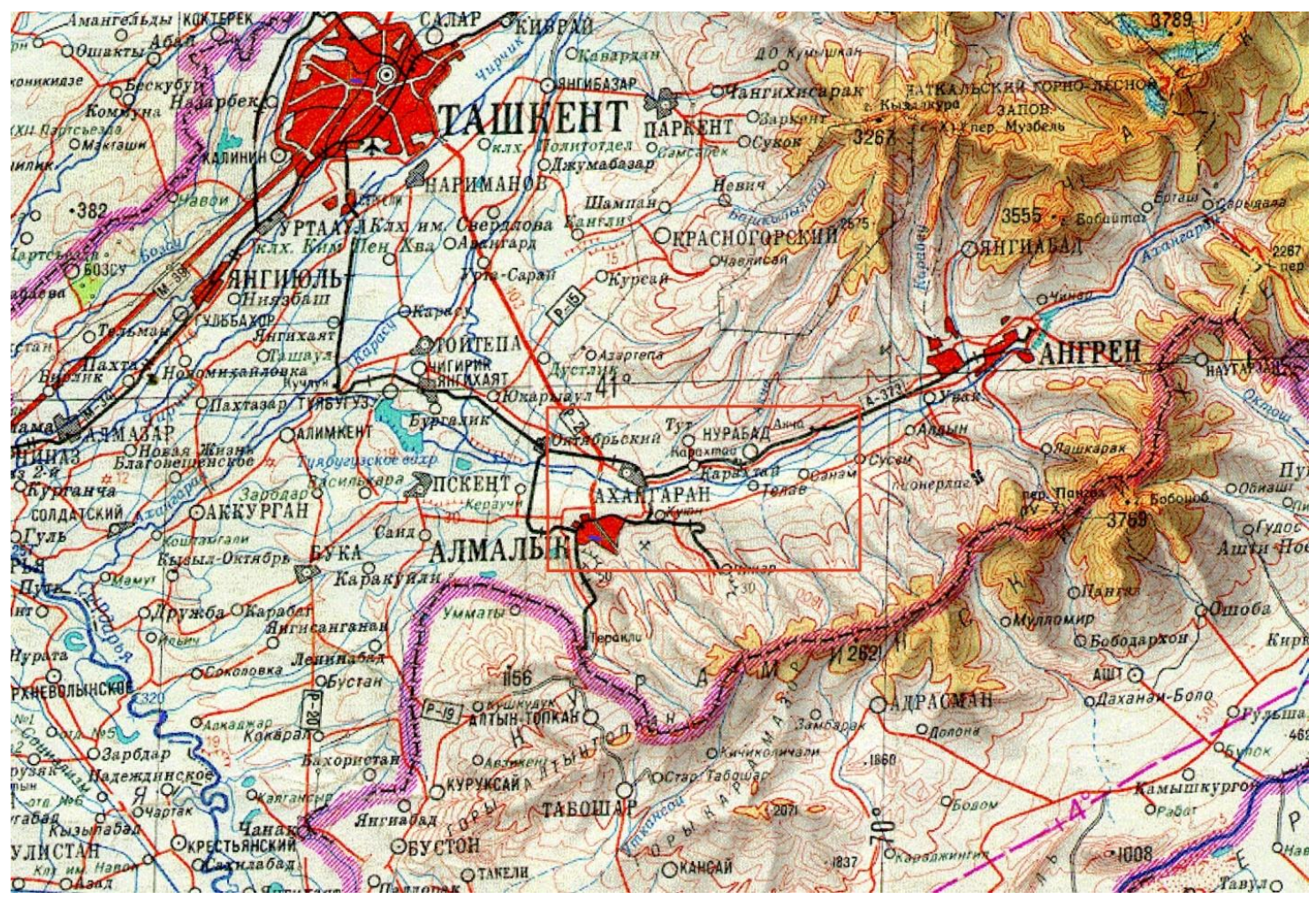

Fig. 2. Overview map, training area

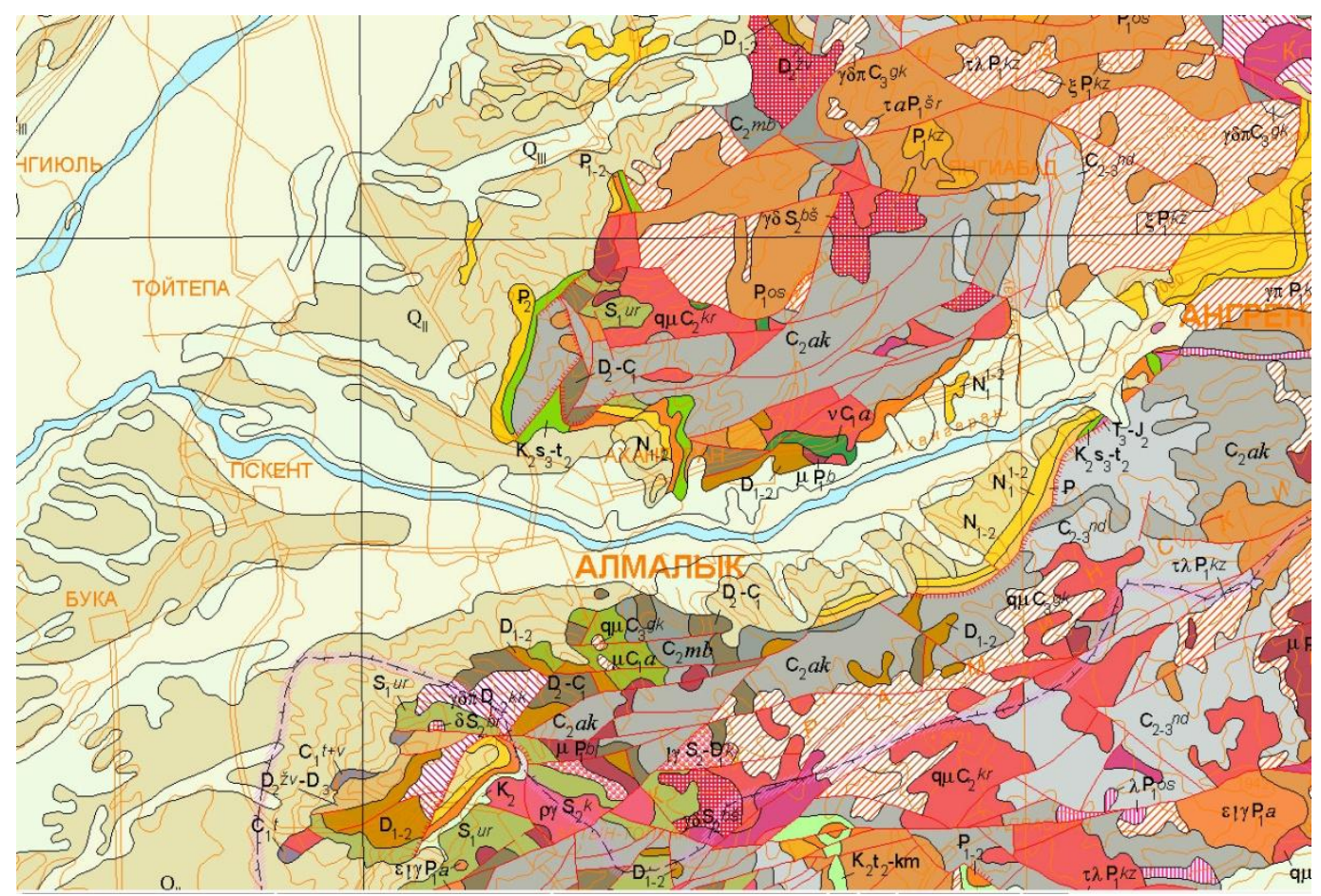


Fig. 3. Geological map of the study area

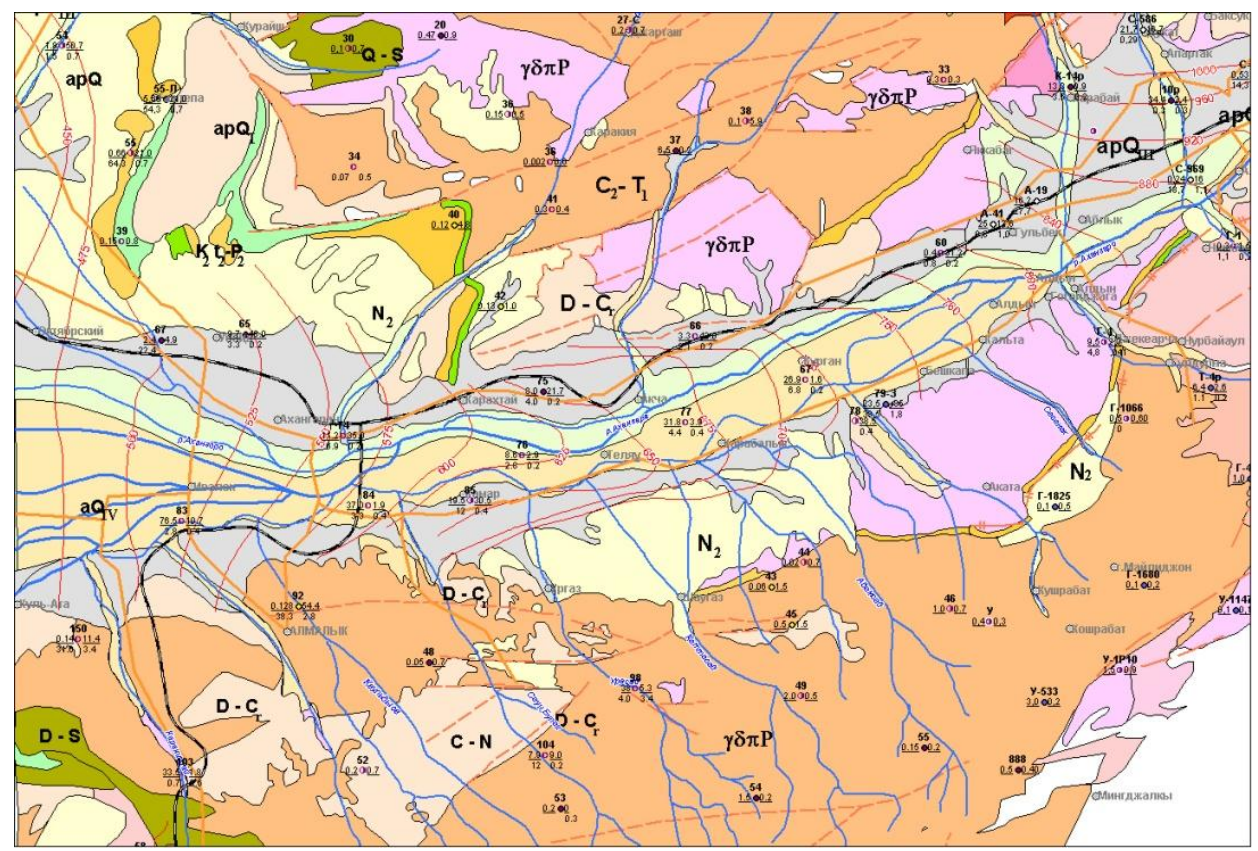

Fig. 4.Schematic hydrogeological map of the research area

To form a geofiltration model, filtration coefficients were introduced for each calculation layer. During the solution, the water conductivity is calculated using the entered filtration coefficients and the absolute marks of the upper and lower boundaries of each layer.

The discussion of the results. As a result of the work, several versions of the photorealistic model were obtained, but these are only the first steps towards a comprehensive system that provides for the possibility of geofiltration and geomigration modeling, as well as three-dimensional display of the results of modeling of research territories (Fig. 2). 


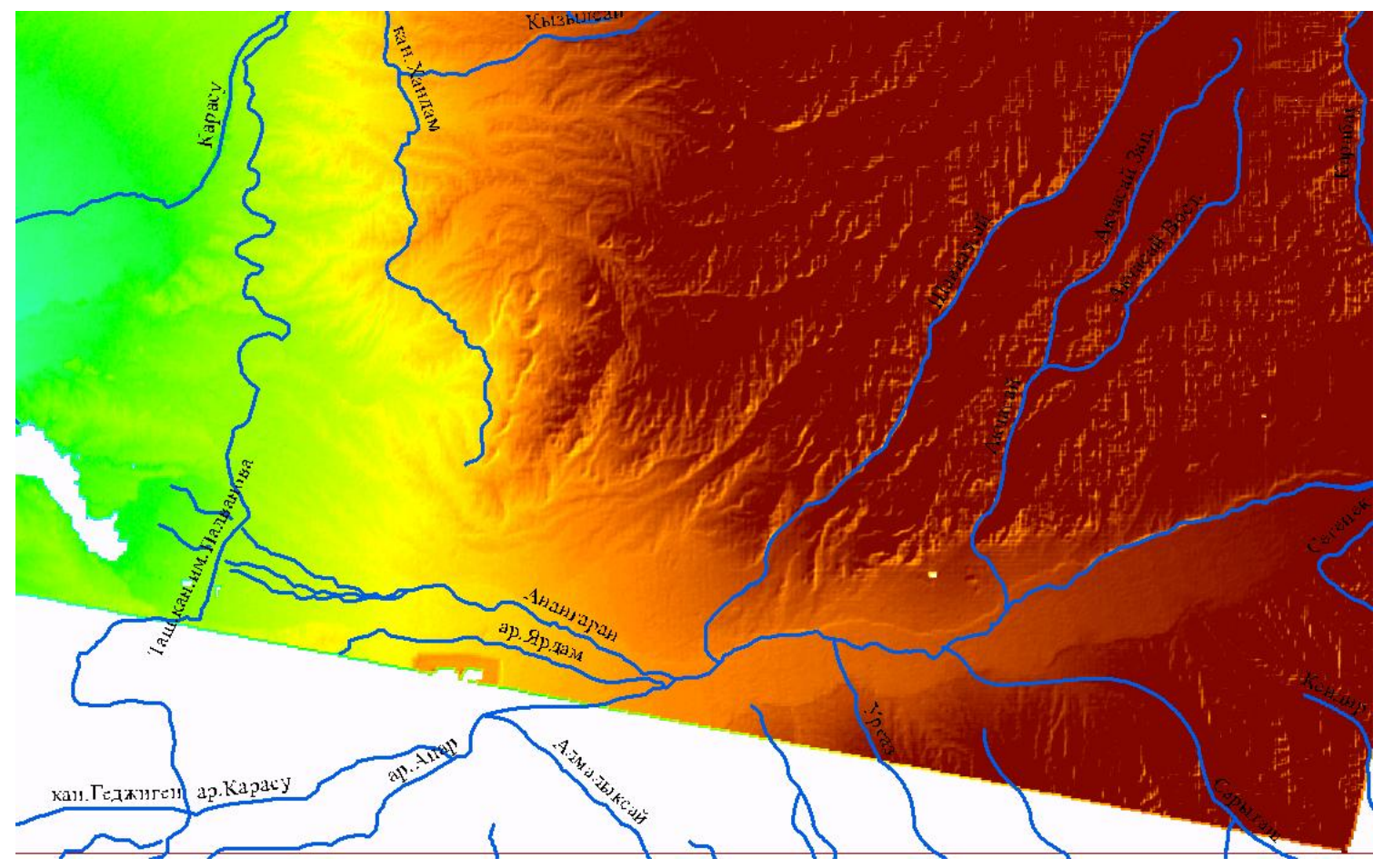

Fig. 2.3D view of the object

Operational monitoring, the most characteristic for the boundary representation, is considered; calculation of the overall volume; calculating the normal at a point; calculation of surface curvature; finding the point of intersection with the beam or curve; determining the position of a point relative to the surface.

The basic operations include transforming materials on a GIS basis and creating a primitive, its modification, local modification of curves and surfaces, automatic construction of fillets, joints and cross-linking of surfaces, automatic search for intersections, rotation, extrapolation of data, as well as transforming an object into a plane [Djumanov J.X., 2016, p.258],[Yurkov V.Yu.,2006, p.96]. Surface modeling is the basis for the construction of geofiltration and geomigration models, nodes and the integration core.

\section{CONCLUSION}

The tasks of geofiltration and geomigration modeling of groundwater and visualization is an important area of computer graphics. Since data on physical objects of the real world cannot be entirely entered into a computer, it is necessary to a priori limit the amount of information about an object within the framework of the issue of interest to us. For example, the task of GIS rendering an object with shading raises such problems as: Mineralization and mass transfer of the underground hydrosphere, how to visualize, What parts of the object are visible?, What color should be assigned to each element of the object?

In a generalized form, it looks as follows: the characteristic of the projection apparatus, the construction of images of the main geofiltration and geomigration elements, the work with the constructed images in accordance with the geographic coordinate reference. 
A research technique has been developed to simulate geofiltration and geomigration processes, to determine the balance of groundwater, and the hydrogeological parameters of the aquifer have been calculated from it. The features are considered and the boundary and initial conditions are justified.

The calculated values of the natural resources of groundwater by the parameters of their level mode in the Ahangaran pool allowed:

- establish the permissible convergence (3.9$25.9 \%$ ) of resource estimates according to the amplitudes of fluctuations in the level of groundwater and according to geometric modeling of groundwater fields;

Based on the assessment of changes in the hydrodynamic and hydrochemical parameters of groundwater, it was revealed that the level mode in the riverine zone and in the valleys of natural sai is closely interconnected with runoff in the watercourse, where level fluctuations depend on the water content of the year. Relative to the last low-water $2010 \mathrm{y}$, the average annual levels of PV are everywhere within the indicated zones during 2014-2016 tended to rise.

The level mode of groundwater within the high terraces of fields where irrigated agriculture is developed depends on the type of crops grown and the rate of irrigation. Therefore, the rate of fluctuation of average annual levels and their absolute value are not unambiguous in individual areas and to a less extent depend on the water content of the year.

\section{REFERENCES}

1. Abutaliev F.B, Khabibullaev I. Solution of the problem of filtering multilayer aquifers // Modern methods of research and data processing in hydrogeology. Issue No. 6. Tashkent 1980 -pp. 15-22.

2. Anderson D., Tonnichell D., Pletcher R. Computational hydromechanics and heat transfer. $-M$.: World. 1990. T.I. -p.352

3. Bindeman N.A. Assessment of operational groundwater reserves. Moscow. Gosgeoltekhizdat, 1963

4. Djumanov J.X. Mathematical modeling of geofiltrational of processes of the regional hydrogeological systems // Vienna, Austria. European Science Review. 2016. No. 11-12. -pp.28-33.

5. Djumanov J.X. Geoinformation technologies in hydrogeology // Monograph, ed. SE "Institute of HYDROINGEO”, 2016. -p.258

6. Fletcher K. Computational methods in fluid dynamics. - M .: Mir, 1991.- T.1, 2. p. 552

7. Khabibullaev I. Numerical modeling of groundwater filtration of irrigated massifs and application packages. -T.: Fan. 1991. -p.115

8. Mavlonov A.A., Khabibullaev I., Djumanov J.X. // Geology and Mineral Resources. T., - 2010. - No. 5.-pp. 35-36.

9. Mavlonov A.A., Borisov V.A., Djumanov J.X. Monitoring of groundwater of irrigated lands and desert territories of the Republic of Uzbekistan. Drinking groundwater. Study, use and information technology // Materials international. scientific conf. Part 3. Moscow Region, Green 2011 -pp.269-278.

10. Mirzaev S.Sh. Groundwater reserves. Tashkent: "Fan", 1974.

11. Rakhmatullayev Sh, Frederic H, Kazbekov J, Philippe C. Djumanov J. Groundwater resources of Uzbekistan: an environmental and operational overview /l Central European Journal of Geosciences // SPRINGER-Versita. Germany 2012. No4 (1) -pp. 67-80

12. Saidmuradov Zh.Z., Djumanov J.X., Chertkov Yu.T., Saidmuradov Z.S., Eshankulov O.R. To the issue of 
substantiating sources of household water supply to rural settlements (on the example of the Tashkent region) // Problems of providing water resources to rural settlements in dry years and ways to solve them // Materials. Republic scientific conf. Tashkent 2008 -pp.116-119

13. Samarsky A.A. Theory of difference schemes. $-M$.: Science. 1983. -p.616

14. Umarov U. U. "Methods of mathematical modeling of hydrogeological processes" Tashkent: Fan. 1966.-p.112

15. Umarov U. U. Automation information retrieval system "Land reclamation hydrogeology" and permanent models. Tashkent: Fan. 1978. -p.120

16. Usmanov R.K., Dzhumanov Zh.Kh., Rasulev B.T., On the integration of the fuzzy-plural approach into the process of numerical modeling of the hydrogeological conditions of the Kibray water intake // Ecological Bulletin. -T. 2007 No. 8. -pp.37-39

17. Verigin N.N., Vasiliev S.V., Kuranov N.P. et al. Methods for predicting the salt mode of soils and groundwater. -M.: Kolos, 1979.- p.336

18. Hasanov A.S. Development of hydrogeology and engineering geology in Uzbekistan. - Tashkent: HYDROINGEO, 2005, -p.212

19. Yurkov V.Yu. Interval and fuzzy geometry in the system of development and diagnosis of the spatial factor of intelligence / Omsk Scientific Bulletin. 2006. - No. 2 (35)-pp. 96-99.

20. Zlotnik V.A., Kalinin M.Yu., Prediction of the effect of groundwater exploitation on hydrogeological conditions. Minsk. "Science technology. 1985, -p.296 